\title{
Substances from the medicinal mushroom Daedalea gibbosa inhibit kinase activity of native and T315I mutated Bcr-Abl
}

\author{
MAJED YASSIN $^{1,2}$, SOLOMON P. WASSER ${ }^{2}$ and JAMAL MAHAJNA ${ }^{1}$ \\ ${ }^{1}$ Cancer Drug Discovery Program, Migal, Galilee Technology Center, P.O. Box 831, \\ Kiryat Shmona; ${ }^{2}$ Institute of Evolution, University of Haifa, Mount Carmel, Haifa 31905, Israel
}

Received January 24, 2008; Accepted March 21, 2008

\begin{abstract}
Human chronic myelogenous leukemia (CML) is a malignancy of pluripotent hematopoietic cells characterized by a distinctive cytogenetic abnormality resulting in the creation of a p210 ${ }^{\mathrm{Bcr}-\mathrm{Abl}}$ fusion protein with abnormal tyrosine kinase activity. Recently, a selective Abl kinase inhibitor, Imatinib mesylate, was introduced as a first line therapy for CML. Despite the initial response, CML patients develop a resistantance to Imatinib, which is mediated mainly by point mutations within the Abl protein. Herein, we describe the identification of mycelium organic extracts of Daedalea gibbosa with selective anti-proliferating and apoptosisinducing activities against K562 cells and other laboratory model of CML. Using activity-guided purification, we isolated an active fraction, F6, which inhibits in vitro kinase activity of recombinant Abl. The active fraction significantly inhibits the autophosphorylation of native and mutated Bcr$\mathrm{Abl}$, which are resistant to Imatinib treatment including the T315I mutation. Using a colony-forming assay, we demonstrated that the active fraction is effective in inhibiting the colony formation of the $\mathrm{Ba} / \mathrm{F} 3$ cell line harboring either native Bcr-Abl or its mutations, including the T315I mutation. Our data illustrated the potential of natural products in cancer therapeutics.
\end{abstract}

\section{Introduction}

Medicinal mushrooms have been an important source of therapeutic substances for the treatment of various human illnesses (1). Higher basidiomycetes mushrooms (HBM) represent a major and, as yet, largely untapped source of potent new pharmaceutical products. Of the 15,000 known

Correspondence to: Dr Jamal Mahajna, Cancer Drug Discovery Program, Migal, P.O. Box 831, Kiryat Shmona 11016, Israel E-mail: jamalm@migal.org.il

Key words: medicinal mushrooms, Daedalea gibbosa, antitumor activity, differentiation, Bcr-Abl, kinase, apoptosis, chronic myelogenous leukemia species, 2,000 are safe for human health and $\sim 650$ of them possess medicinal properties (2). Of the 650 mushroom species with known medicinal properties, only 20 species are already in use (3), arguing the need to explore the medicinal potential of the rest.

Several medicinal mushroom substances having anti-tumor activity were isolated including lentinan, krestin and schizophyllan. Most bioactive substances isolated from mushrooms were high-molecular-weight (HMW) polysaccharides having a molecular weight of 200-400,000 Dalton. Anti-tumor activity of HMW polysaccharides was attributed to immunemodulation function or enhancement properties of the immune system, not as a result of a direct influence on the tumor cells. Our interest is in low-molecular-weight (LMW) moieties that can easily penetrate the cell membrane and exhibit anti-tumor activity with a defined mechanism of action (4-8).

Chronic myelogenous leukemia (CML) is a clonal myeloproliferative disorder of hematopoietic stem cells and accounts for $15 \%$ of leukemias in adults (9). Blasts of patients suffering from CML in $>95 \%$ of cases the Philadelphia chromosome, the morphological substrate of $t(9 ; 22)$. Patients (25-30\%) from adult lymphoblastic leukemia (ALL) are $\mathrm{Ph}^{+}$ ALL and the presence of $t(9 ; 22)$ defines a high-risk subgroup of ALLs (9).

The $\mathrm{t}(9 ; 22)$-related translocation products are the Bcr-Abl fusion proteins. The fusion of Bcr to Abl leads to the constitutive activation of the kinase activity of Abl, whose physiological counterpart is finely regulated by a variety of stimuli. Constitutively activated Abl induces aberrant proliferation and neoplastic transformation by the constitutive activation of RAS, PI3 kinase, as well as JAK/STAT (9). The constitutively activated Abl kinase activity is indispensable for the Bcr-Abl-induced transformation of cells. The Bcr-Ablinduced phenotype of hematopoietic cells is characterized by increased proliferation as well as by reduced susceptibility to a variety of pro-apoptotic stimuli, including growth factor deprivation (9). The inoculation of stem cells retrovirally transduced with Bcr-Abl induces a CML-like disease in sublethally irradiated recipient mice within 3-4 weeks, which proves that $\mathrm{Bcr}-\mathrm{Abl}$ is responsible for the pathogenesis of $\mathrm{Ph}^{+}$ leukemias (10).

The inhibition of Bcr-Abl kinase activity is a valid concept of causal therapy of $\mathrm{Ph}^{+}$leukemia and the specific $\mathrm{Abl}$ kinase 
inhibitor Imatinib mesylate (Imatinib, Gleevec, and before STI571) is now a part of standard therapy of chronic phase CML (CP) and is included in most clinical trials for the treatment of $\mathrm{Ph}^{+}$ALL (11-13). Unfortunately, the clinical efficacy of the treatment with Imatinib continuously decreases with the advancement of the disease. Blast crisis, CML or relapsed $\mathrm{Ph}^{+} \mathrm{ALL}$ benefit from the treatment of Imatinib only temporarily or not at all (14). Patients relapsing upon treatment with Imatinib are resistant to further treatment with the drug.

Secondary resistance is mostly due to the acquisition of point mutations in Bcr-Abl, which change the affinity of the protein for Imatinib. More than 25 different substitutions of amino acid residues of $\mathrm{Bcr}-\mathrm{Abl}$ have been detected in $\mathrm{CML}$ and $\mathrm{Ph}^{+}$ALL patients (15-17). Such mutations can pre-exist at the onset of treatment in a small subset of cells, which are selected by the treatment with Imatinib (18). Even mutations outside the kinase domain contribute to Imatinib resistance by stabilizing the active conformation, which is not accessible by Imatinib.

Several new Abl inhibitors were reported; AMN107, BMS354825 and VX-680. AMN107 is a novel ATP-competitive inhibitor of Abl with increased potency compared with Imatinib in inhibiting cellular proliferation and was also more effective than Imatinib in inhibiting phosphorylation of $\mathrm{p} 185$ Bcr-Abl tyrosine kinase in cell lines and in primary ALL cells. AMN107 is effective against a variety of cell lines expressing Imatinib-resistant Bcr-Abl mutants, except for the T315I mutation (29).

BMS-354825 is another novel compound, which is a dual $\mathrm{Src} / \mathrm{Abl}$ kinase inhibitor having a greater potency than Imatinib and is active against 14 of the 15 Imatinib-resistant Bcr-Abl mutants (16). The T315I mutation in the kinase domain of Abl was resistant to inhibition by Imatinib, AMN107 and BMS354825 (19). VX-680 compound was developed as Aurora A kinase inhibitor and later turned out to inhibit Abl kinase and its mutants including T315I mutation by a novel mechanism (20). Treatment of Imatinib-resistant patients carrying the T315I with VX-680 resulted in a promising outcome $(20,21)$.

Herein, we report the identification of a mycelium organic extract from Daedalea gibbosa having selective antiproliferating and apoptosis-inducing activities against K562 cells and other laboratory model of CML. In addition, we identified an active fraction, F6, capable of directly inhibiting the kinase activity of recombinant Abl, as well as its autophosphorylation activity of native Bcr-Abl and its mutated forms including the T315I mutation. The active fraction of D. gibbosa also inhibited the colonigenicity of native Bcr-Abl and its mutants when expressed in $\mathrm{Ba} / \mathrm{F} 3$ cell lines.

\section{Materials and methods}

Mushroom material. The strain D. gibbosa used in the present study is from the culture collection of HBM (HAI) of the Institute of Evolution, University of Haifa, Israel (22). Mushroom growth medium and the cultivation of $D$. gibbosa as previously described (4).

Mushroom growth conditions and extractions. Pre-inocula for cultures were prepared by transferring to 5-mm diameter discs to flasks containing $100 \mathrm{ml}$ of YE medium (yeast extract
$0.1 \%$, peptone $0.1 \%$, glucose $2 \%, \mathrm{KH}_{2} \mathrm{PO}_{4} 0.1 \%, \mathrm{MgSO}_{4}$ $0.05 \%$, supplemented with $10 \mathrm{ml} / 1$ of trace solution $(18 \mathrm{mM}$ $\mathrm{FeSO}_{4}, 3.7 \mathrm{mM} \mathrm{MnSO}{ }_{4}, 1.5 \mathrm{mM} \mathrm{ZnSO}_{4}$ and $0.8 \mathrm{mM} \mathrm{CuSO}_{4}$ ) incubated for 14 days. The contents of the pre-inocula flasks were homogenized and transferred to flasks containing 1 litre of YE medium. Inoculated flasks were shaken at $160 \mathrm{r} / \mathrm{min}$ at $27^{\circ} \mathrm{C}$ for 12 days, then filtered and washed to remove culture broth. Wet mycelia were dried at $37^{\circ} \mathrm{C}$. In the first phase of the study; dry mycelium were extracted as previously described (4). At a later stage, extraction was carried out using $100 \%$ dichloromethane (DCM) or $100 \%$ ethyl acetate (EA).

Fractionation of mycelium crude extract. Daedalea gibbosa crude extract $(1.5 \mathrm{~g})$ was prepared from $85 \mathrm{~g}$ of $D$. gibbosa mycelium, which was extracted with 5 litres of dichloromethane on a rotary shaker at $160 \mathrm{r} / \mathrm{min}$ at room temperature. Dichloromethane extract (1.3 g) was separated in a silica gel column (Silica gel 60, Merck, USA). Different fractions were eluted by increasing methanol concentrations (from 0, 0.25, $0.5,1,2,5,10,20,40,60$ and $100 \%)$. During the fractionation process, the eluted substances were traced by thin layer chromatography (TLC). The separated substances were visualized by staining with $2 \%$ phosphomolybdic acid.

Cell lines and cell cultures. $\mathrm{Ba} / \mathrm{F} 3$ cells (a murine pro-B cell line) transfected with native Bcr-Abl, Bcr-Abl/T315I, or Bcr-Abl/E255K constructs were donated by Dr J. Duyster, Germany. Transfected Ba/F3 and Human K562 (ATCC, Rockville, MD) cell lines were grown in RPMI-1640 with $2 \mathrm{mM}$ L-glutamine and supplemented with $10 \%$ fetal bovine serum. Penicillin at $100 \mathrm{U} / \mathrm{ml}$ and streptomycin at $100 \mu \mathrm{g} / \mathrm{ml}$ were added to the culture media. Each cell line was grown at $37^{\circ} \mathrm{C}$ in a humidified atmosphere with $5 \% \mathrm{CO}_{2}$.

Bcr-Abl autophosphorylation assay by ELISA. The capture anti-Abl antibody (100 ng/well, Santa Cruz, USA) was first diluted in $0.1 \mathrm{M}$ carbonate buffer, $\mathrm{pH} 9.4$, then $200 \mu \mathrm{l}$ was added to each well of a 96-well plate and the plates were kept at $37^{\circ} \mathrm{C}$ overnight. Cell lysates were prepared from treated and untreated K562 or transfected Ba/F3 cell lines. After treatment for $1 \mathrm{~h}$, cells were washed twice with cold PBS and lysed with lysis buffer [10 mM Tris- $\mathrm{HCl}$ (pH 7.4), $100 \mathrm{mM}$ $\mathrm{NaCl}, 1 \mathrm{mM}$ EDTA, $1 \mathrm{mM}$ EGTA, $1 \mathrm{mM} \mathrm{NaF}, 20 \mathrm{mM}$ $\mathrm{Na}_{4} \mathrm{P}_{2} \mathrm{O}_{7}, 2 \mathrm{mM} \mathrm{Na} \mathrm{VO}_{4}, 1 \%$ Triton X-100, $10 \%$ glycerol, $0.1 \%$ SDS, $0.5 \%$ deoxycholate, $1 \mathrm{mM}$ phenylmethylsulfonyl fluoride] for $30 \mathrm{~min}$ on ice. After blocking the plates for $1 \mathrm{~h}$, the cell lysates (100 $\mu \mathrm{g} /$ well) were diluted in a blocking buffer (PBS, 1\% BSA) and then added to the plates in a volume of $200 \mu 1$ per well, and the plates were incubated at $4^{\circ} \mathrm{C}$ overnight. Subsequently, the plates were washed with wash buffer (PBS, 0.05\% Tween-20) and a reporter antibody PY20 conjugated to HRP was added at $50 \mathrm{ng} /$ well and incubated at room temperature for $1 \mathrm{~h}$. The ELISA was developed using TMB as a substrate and OD was measured at $630 \mathrm{~nm}$.

Cellular autophosphorylation of Bcr-Abl. Ba/F3 cell lines that express the native Bcr-Abl protein and its mutated forms $\left(4 \times 10^{5}\right.$ cells $\left./ \mathrm{ml}\right)$ were treated with mycelium crude extract, fraction 6 of the D. gibbosa extract and DMSO for $1 \mathrm{~h}$. Cells 
Table I. Growth inhibition and induction of erythroid differentiation by D. gibbosa crude extracts.

\begin{tabular}{|c|c|c|c|c|c|c|}
\hline \multicolumn{2}{|c|}{ Extracts } & \multicolumn{4}{|c|}{ Growth inhibition (\%) } & \multirow{2}{*}{$\begin{array}{c}\text { Erythroid differentiation } \\
\text { Relative hemoglobin levels }\end{array}$} \\
\hline Ex & Extract symbol & K562 & DU145 & MH3924A & НТ-29 & \\
\hline Meth451 & Eth & 51.3 & -6.2 & 44 & 0.2 & 10.8 \\
\hline MH56 & $\mathrm{H}$ & 56.3 & 26.2 & 28 & 23.9 & 1.6 \\
\hline ME424 & $\mathrm{E}$ & 45.4 & 11.9 & 54 & 24.50 & 2.3 \\
\hline MC57 & $\mathrm{C}$ & 52.7 & 16.2 & 14 & 7.6 & 1.7 \\
\hline
\end{tabular}

Percentage of growth inhibition caused to a variety of cell lines. Relative hemoglobin levels expressed in treated cells.

were collected, washed once with cold PBS and lysed as previously indicated. Cell lysate supernatants ( $40 \mu \mathrm{g}$ protein) were resolved on $8 \%$ SDS-polyacrylamide gel electrophoresis, transferred to nitrocellulose membranes and analyzed by immunoblotting with phospho-c-Abl (Tyr245) polyclonal antibody (Cell Signaling Technology, USA). Phosphorylated levels of $\mathrm{Bcr}-\mathrm{Abl}$ proteins were compared to total Abl, which was detected using c-Abl monoclonal antibody (Santa Cruz Biotechnology, USA).

Colony forming assay. $\mathrm{Ba} / \mathrm{F} 3$ cells $\left(2 \times 10^{3}\right)$ that express $\mathrm{Bcr}-$ $\mathrm{Abl}$ or its mutated forms (Bcr-Abl/T315I and Bcr-Abl/ E255K) were re-suspended in RPMI-1640 with L-glutamine, supplemented with $10 \%$ fetal bovine serum and containing $0.3 \%$ Noble agar (Sigma, USA). Cells were seeded in 6-well plates above a layer of $0.6 \%$ Noble agar. The cells were fed every two days by overlaying the agar with $3 \mathrm{ml}$ of a medium containing mycelium crude extract, fraction 6 of $D$. gibbosa extract, Imatinib or DMSO. The presence or absence of colonies was scored after 14 days (23).

Abl in vitro kinase assay. The activity of Abl protein kinase using recombinant Abl enzyme (expressed in Sf21 cells from Upstate Cell Signaling Solutions, USA) was assayed in the presence or absence of inhibitors by measuring the incorporation of ${ }^{33} \mathrm{P}$ from $\left[\gamma^{3}{ }^{33} \mathrm{P}\right]$-ATP (PerkinElmir, USA) into Abltide (EAIYAAPFAKKK peptide from Upstate). Imatinib (Novartis, Basel), AG957 (Sigma) and fraction 6 of D. gibbosa (\#514) mycelium crude extract were dissolved and stored at $-70^{\circ} \mathrm{C}$. The Abl protein kinase assay was carried out at $30^{\circ} \mathrm{C}$ in a total volume of $25 \mu \mathrm{l}: 20 \mathrm{ng}$ recombinant $\mathrm{Abl}$ kinase, $50 \mathrm{mM}$ Hepes buffer $\mathrm{pH} 7.4,20 \mathrm{mM} \mathrm{MgCl} 2,0.1 \mathrm{mM} \mathrm{MnCl}{ }_{2}$, $0.2 \mathrm{mM} \mathrm{Na}_{3} \mathrm{VO}_{4}, 1 \%$ DMSO, $25 \mu \mathrm{M}$ ATP $\left(1 \mu \mathrm{Ci} /\right.$ assay $\left[\gamma^{-}{ }^{33} \mathrm{P}\right]-$ ATP) and $200 \mu \mathrm{g} / \mathrm{ml}$ Abltide and was carried out for $10 \mathrm{~min}$. The assay was terminated with the addition of $5 \mu 1$ of $72 \mathrm{mM}$ EDTA. Subsequently, $25 \mu 1$ of the reaction mixture were transferred onto the center of a $2 \times 2 \mathrm{~cm}$ P81 paper (Upstate Cell Signaling Solutions), washed three times for $5 \mathrm{~min}$ with $0.75 \%$ phosphoric acid, then washed once for 5 min with acetone and counted using a liquid scintillation analyzer (TRI-CARB 2100TR, Packard Bio Science Company, USA).

\section{Results}

The medicinal mushroom D. gibbosa was grown as a submerged culture, and four different solvent mixtures including Eth (70\% ethanol), E (33\% ethyl acetate, $50 \%$ methanol), $\mathrm{H}$ (22\% ethyl acetate, $11 \%$ methanol) and $\mathrm{C}(33 \%$ chloroform, $50 \%$ methanol) were used to prepare crude extracts. Initially, growth inhibition activity of the various extracts was monitored utilizing an XTT assay $(4,24)$. The anti-proliferation activity was evaluated using a number of cell lines including HT29 (human colon adenocarcinoma cells), MH3924A (rat Morris hepatoma) and DU145 (human prostate carcinoma).

Results summarized in Table I show that each organic extract of D. gibbosa was significantly active in inhibiting the growth of K562 cells with varying potency and selectivity. Crude extracts H (MH56) and C (MC57) were selective in inhibiting the growth of K562 cells. In contrast, organic crude extract Eth (Meth451) and E (ME424) show significant growth inhibition activity against K562 and MH3924A (rat Morris hepatoma) cell lines, though exhibit minimal activity against HT29 (human colon adenocarcinoma cells) and DU145 (human prostate carcinoma).

Induction of erythroid differentiation in K562 by crude extracts of Daedalea gibbosa. Overexpression of p210 Bcr-Abl is implicated in mediating arrested differentiation and resistance to apoptosis (25). K562 are patient-derived cell lines (26) and serve as the in vitro CML model. K562 cell lines are pluripotent cells that are able to undergo differentiation along megakaryocytic and erythroid lineages $(4,27)$. Induction of differentiation in CML patients might serve as a potential route for CML therapy. Extracts of D. gibbosa were evaluated for their ability in inducing erythroid differentiation in K562 cell lines. The ability to induce erythroid differentiation was monitored by measuring hemoglobin production in treated cells. Results shown in Table I demonstrate that crude extracts of $D$. gibbosa show a varying potency in inducing hemoglobin expression in treated cells. Extracts Meth451 and ME424 induce hemoglobin expression by 10.8- and 2.3-fold, respectively, above the solvent-treated cells. Notably, extract Eth shows the highest activity of hemoglobin production and was more potent than that of butyric acid (4), a well established differentiation agent.

Growth inhibition of K562 by D. gibbosa extracts is mediated by the induction of the apoptosis pathway. Induction of apoptosis is the principle mechanism by which the majority of chemotherapeutic agents exert their function. The execution of apoptosis requires specific caspases including 
$\underline{\mathbf{A}}$

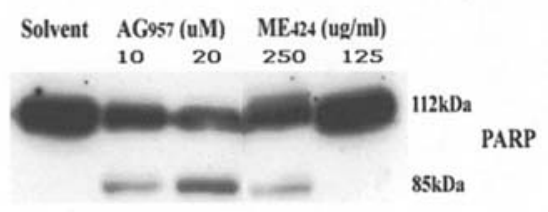

B

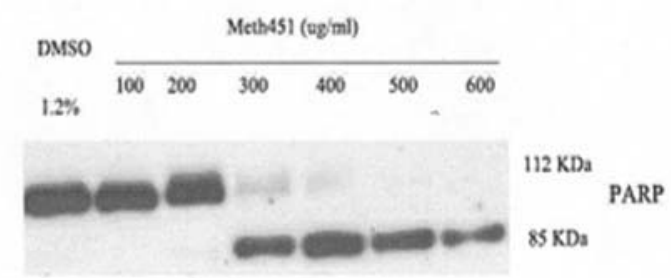

Figure 1. Induction of apoptosis by D. gibbosa crude extracts. (A) and (B) induction of PARP cleavage in treated cells by ME424 (A) and Meth451 (B).

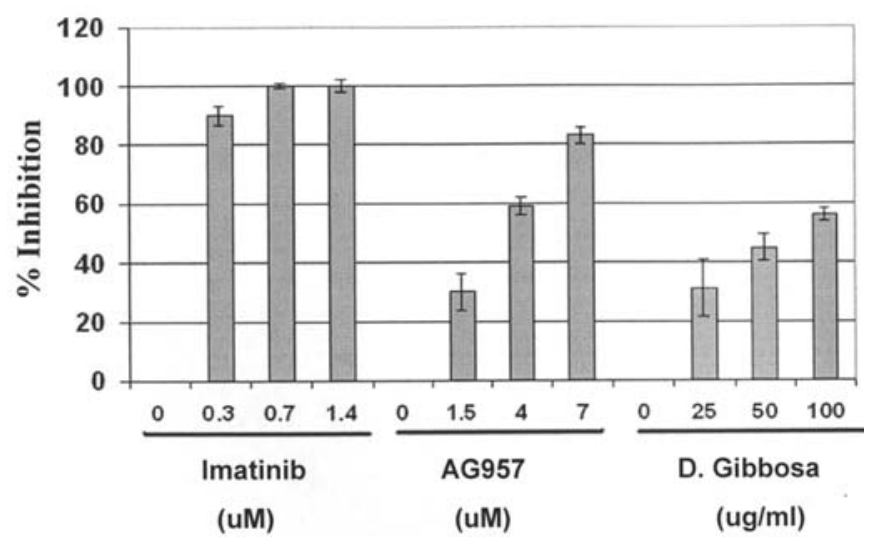

Figure 2. Inhibition of Bcr-Abl phosphorylation using ELISA assay. Cells were treated with the indicated concentration for $1 \mathrm{~h}$ and $100 \mu \mathrm{g}$ of proteins were used to determine levels of phopshorylated Bcr-Abl.

caspase-3, which cleaves death substrates such as the nuclear protein poly (ADP-ribose) polymerase (PARP). In this study, we followed PARP cleavage as an endpoint for apoptosis assessment (28).

Consistent with published data, treatment with AG957, a known substrate inhibitor of Abl, causes a significant cleavage of PARP. Crude extract $E$ and Eth were active in inducing apoptosis in treated K562 cell lines as determined by the PARP cleavage assay (Fig. 1).

Effect of Daedalea gibbosa crude extract on the autophosphorylation of Bcr-Abl. The creation of Bcr-Abl fusion protein resulted in enhanced and uncontrolled tyrosine kinase activity of the p210 ${ }^{\mathrm{Bcr}-\mathrm{Abl}}$. It is well documented that tyrosine kinase activity is responsible for the oncogenic potential of Bcr-Abl. A number of anti-CML compounds, including Imatinib (Gleevec) and the tyrphostin AG957, are known to inhibit tyrosine phosphorylation of Bcr-Abl and consequently exert anti-CML effects. In order to investigate the mechanism of action by which the organic extract of $D$. gibbosa exerted its function, we followed levels of phosphorylated Bcr-Abl protein. For this purpose, we developed an ELISA assay in which a monoclonal anti-c-Abl antibody (Santa Cruz) is used to capture the Bcr-Abl and c-Abl protein, while the anti-phosphorylated tyrosine antibody, PY20, is used as a reporter antibody. Initially, we monitored phosphorylated c$\mathrm{Abl} / \mathrm{Bcr}-\mathrm{Abl}$ in a variety of cell lines such as K562, LNCaP, Cos- 1 and $\mathrm{Ba} / \mathrm{F} 3$ p185 Bcr-Abl. The signal obtained was very minimal in LNCaP and Cos- 1 cells. Furthermore, signals from K562 and Ba/F3 p185 Bcr-Abl cells were significantly higher than the background signal. However, signal-to-noise ratio from Ba/F3 p185 Bcr-Abl was reproducibly and significantly better than that obtained with the K562 cells. Thus, we proceeded to investigate the ability of the D. gibbosa extract in affecting phosphorylation of Bcr-Abl using $\mathrm{Ba} / \mathrm{F} 3$ p185 Bcr-Abl. Ba/F3 p185 Bcr-Abl cells were treated with various concentrations of test compounds for $1 \mathrm{~h}$ and levels of phosphorylated Bcr-Abl were measured as described in Material and methods. Results shown in Fig. 2 demonstrate that treatment with Imatinib at $0.35-1.5 \mu \mathrm{M}$ caused a significant reduction in the phosphorylation status of $\mathrm{Bcr}-\mathrm{Abl}$. In addition, treatment with AG957 caused an inhibition of the phosphorylation levels of Bcr-Abl in a concentrationdependent manner. Treatment with $1.75 \mu \mathrm{M}$ of AG957 cause a reduction of $\sim 30 \%$ of in phosphorylation of $\mathrm{Bcr}-\mathrm{Abl}$. Increasing the drug concentration to $7 \mu \mathrm{M}$ caused $>80 \%$ inhibition of the phosphorylation levels of Bcr-Abl. Similarly, treatment with $70 \%$ ethanol extract of D. gibbosa (Meth 451) causes a decrease in the phosphorylation levels of Bcr-Abl. The effect of $D$. gibbosa extract exhibited a concentrationdependent phenomenon. Treatment with $100 \mu \mathrm{g} / \mathrm{ml}$ of $D$. gibbosa extract caused an almost $50 \%$ inhibition in phosphorylation levels of Bcr-Abl. These data argue that the anti-CML activity of $D$. gibbosa extracts might be mediated by the inhibition of autophosphorylation of Bcr-Abl.

Identification of the active fraction that inhibits Abl phosphorylation. In an attempt to identify the active moieties that mediate the activity of the mushroom extracts $D$. gibbosa against K562, we used an activity-guided approach to isolate the active fraction using liquid chromatography. Crude organic extract was separated on a Silica gel using dichloromethane and the concentration of methanol was increased. Fractions were tested for their ability to inhibit autophosphorylation of Bcr-Abl using our ELISA assays that measure tyrosine phosphorylation of Abl proteins. As shown in Fig. 3, fractions F5-F6 contained potent activity that inhibited the autophosphorylation of Bcr-Abl, while fraction F7-F8 showed a moderate inhibitory activity against Bcr-Abl autophopshorylation. In contrast, fractions F2-F4 showed minimal autophosphorylation inhibitory activity. We focused on the fraction F6, which was the most active fraction for the upcoming analysis.

Fraction 6 of the D. gibbosa extract inhibits the autophosphorylation of Bcr-Abl harboring mutations responsible for Imatinib resistance. To investigate whether fraction 514 F6 is active against mutated $\mathrm{Bcr}-\mathrm{Abl}$ found in patients' refractory 


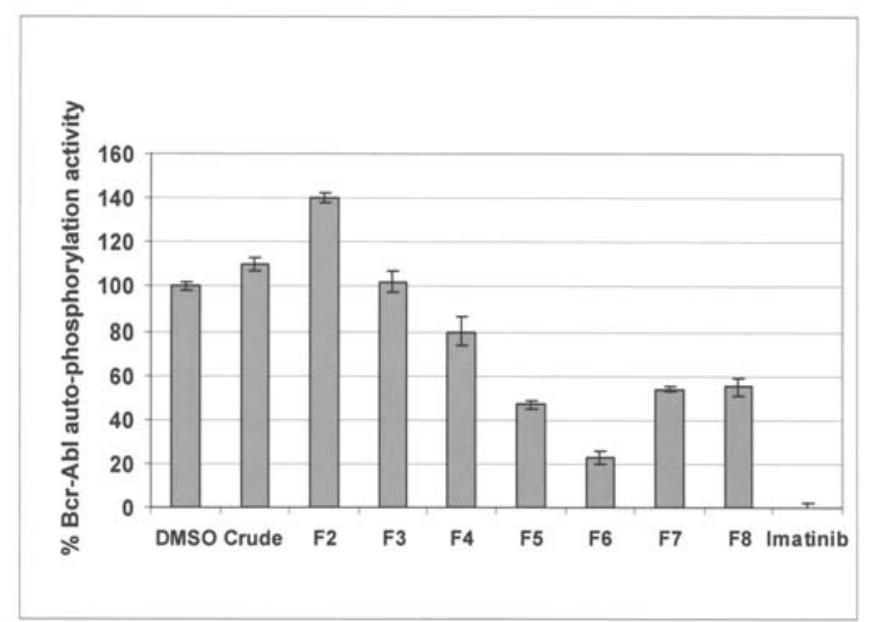

Figure 3. Inhibition of autophosphorylation of Bcr-Abl by D. gibbosa fractions. D. gibbosa fractions were isolated as described in Materials and methods and were used to evaluate the ability to inhibit Bcr-Abl autophosphorylation. K562 cells were treated with appropriate concentrations of the fractions for $1 \mathrm{~h}$ and cell lysates were used to measure levels of Bcr-Abl tyrosine phosphorylation as described in Materials and methods.

to Imatinib treatment, the effect of fraction F6 on the autophosphorylation of Bcr-Abl stably expressed in $\mathrm{Ba} / \mathrm{F} 3$ cells was monitored. Bcr-Abl constructs were used harboring either the $\mathrm{E} 255 \mathrm{~K}$, one of the most frequent mutations in $\mathrm{Ph}^{+}$ ALL patients, or the T315I mutation, which confers resistance not only against Imatinib, but also against most other Abl kinase inhibitors $(16,29,30)$. Levels of phosphorylated Bcr-Abl in relation to levels of total Bcr-Abl were determined using Western blotting. As shown in Fig. 4, crude extract as well as fraction F6 were able to inhibit the autophosphorylation of not only the native Bcr-Abl but also of the two mutations Bcr$\mathrm{Abl}$; E255K and T315I.

Fraction 6 of the D. gibbosa extract inhibits the colonigenicity of Ba/F3 cells expressing Bcr-Abl harboring mutations responsible for Imatinib resistance. In order to evaluate the biological relevance of the inhibition of the autophosphorylation of $\mathrm{Bcr}-\mathrm{Abl}$ and its kinase mutants, the effect of fraction $\mathrm{F} 6$ on the colonigenicity of $\mathrm{Ba} / \mathrm{F} 3$ cells expressing native $\mathrm{Bcr}-\mathrm{Abl}$ and its mutants was studied. $\mathrm{Ba} / \mathrm{F} 3$ cells expressing native $\mathrm{Bcr}-\mathrm{Abl}, \mathrm{Bcr}-\mathrm{Abl} / \mathrm{T} 315 \mathrm{I}$ or $\mathrm{Bcr}-\mathrm{Abl} / \mathrm{E} 255 \mathrm{~K}$ were plated in the absence of IL-3 in a semi-solid medium and in the presence and absence of appropriate treatments. Exposure to fraction F6 as well as to the D. gibbosa crude extract abolished like Imatinib, the colonigenicity of Bcr-Abl-positive $\mathrm{Ba} / \mathrm{F} 3$ cells. While in $\mathrm{Ba} / \mathrm{F} 3$ cells expressing the Bcr-Abl/ T315I or Bcr-Abl/E255K, no inhibition of colonigenicity was seen upon exposure to Imatinib; fraction F6 as well as D. gibbosa organic crude extract completely abrogated the colony formation of these cells (Fig. 5).

Fraction 6 of D. gibbosa inhibits Abl kinase activity. Previously, we showed that fraction F6 inhibits the autophosphorylation of $\mathrm{Bcr}-\mathrm{Abl}$ in $\mathrm{Ba} / \mathrm{F} 3$ cells trasfected with Bcr-Abl constructs. Since the experiment was carried out in cells, one might argue that the observed effect against Bcr-Abl is indirect and not due to the direct inhibition of the kinase
$\underline{\mathbf{A}}$

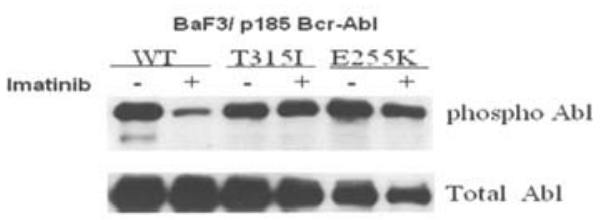

$\underline{\mathbf{B}}$

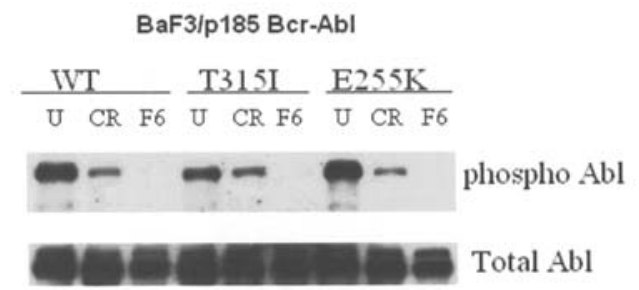

Figure 4. Inhibition of $\mathrm{Abl}$ autophosphorylation of native $\mathrm{Abl}$ and its mutants by Imatinib (A), crude extract (CR) and fraction 6 (F6) (B) compared to solvent-treated samples $(\mathrm{U}) . \mathrm{BaF} / 3$ cells carrying either native $\mathrm{p} 185 \mathrm{Bcr}-\mathrm{Abl}$ or its mutated forms E255K or T315I were treated for $1 \mathrm{~h}$ with Imatinib (1 $\mu \mathrm{M})$, crude extract $(\mathrm{CR})$ or active fraction F6 as described in Materials and methods.

activity of Bcr-Abl. Thus, we tested the activity of fraction F6 on the kinase activity of recombinant Abl kinase using Abltide (EAIYAAPFAKKK) as a substrate.

Results shown in Fig. 6 indicate that fraction F6 inhibited the in vitro kinase activity of recombinant Abl protein, arguing that fraction F6 contains substances that directly interfere with the Abl kinase activity. The experiment was repeated three times with a comparable outcome. Furthermore, Imatinib at $1 \mu \mathrm{M}$ was able to inhibit Abl kinase activity by almost $50 \%$. Similarly, AG957 was active in inhibiting Abl kinase by $50 \%$ at a concentration of $5 \mu \mathrm{M}$.

\section{Discussion}

CML is a malignancy of pluripotent hematopoietic cells characterized by the presence of the Philadelphia $(\mathrm{Ph})$ chromosome, which resulted from reciprocal translocation between the long arms of chromosomes 9 and $22\{(\mathrm{t}(9 ; 22)$ $\mathrm{q} 34 ; \mathrm{q} 11)\}$ resulting in the creation of the fusion gene $\mathrm{p} 210^{\mathrm{Bcr}-\mathrm{Abl}}$ exhibiting abnormal tyrosine kinase activity. The presence of active p210 ${ }^{\mathrm{Bcr}-\mathrm{Abl}}$ renders CML cells resistant to apoptosis and delays differentiation.

Medicinal mushrooms have been an important source of therapeutic substances for the treatment of various human diseases. Anti-tumor activities from mushrooms were described in many reports $(1,2,4-7)$.

In many cases, activity was due to HMW polysaccharides having a molecular weight of 200-400,000 Dalton. Antitumor activity of HMW polysaccharides was attributed to the immune-modulation function or enhancement properties of the immune system, not as a result of a direct influence on the tumor cells.

In this study, we identified mycelium crude extracts of D. gibbosa, which showed anti-tumor effects against the CML 

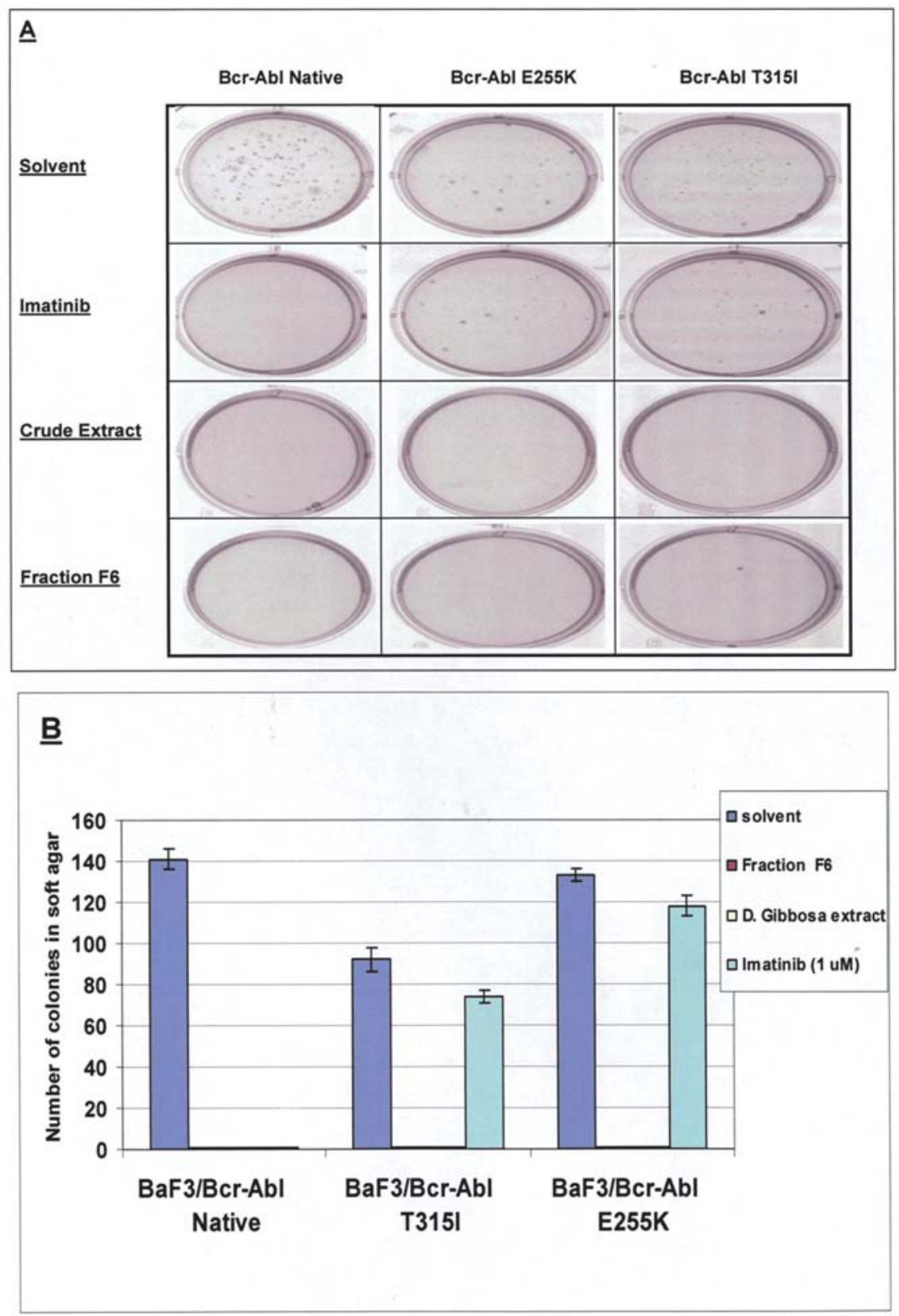

Figure 5. Effect of active fraction F6 and crude D. gibbosa extract compared to Imatinib on the clonogenicity of $\mathrm{Ba} / \mathrm{F} 3$ cells expressing either native or mutated Bcr-Abl (A). (B) A number of stained colonies found in each treatment.

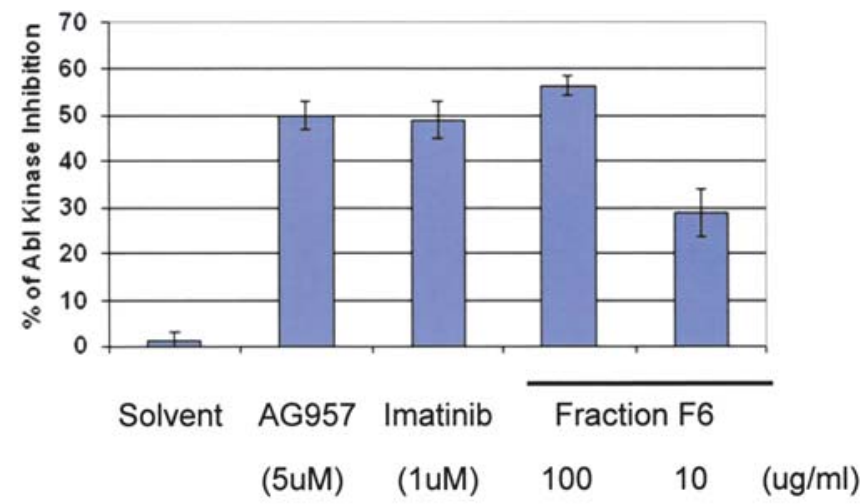

Figure 6. Inhibition of Abl in vitro kinase activity by D. gibbosa active fraction. The Abl in vitro kinase assay was performed according to Materials and methods in the presence of AG957 $(5 \mu \mathrm{M})$, Imatinib $(1 \mu \mathrm{M})$ and $D$. gibbosa active fraction F6 (10 and $100 \mu \mathrm{g} / \mathrm{ml})$. cancer cell line. The anti-CML activity of $D$. gibbosa was observed with each organic extraction; however, selectivity against other tested cancer cell lines was dependent on the composition of solvents used during the extraction. For example, extracts prepared using mixtures $\mathrm{H}$ (22\% ethyl acetate, $11 \%$ methanol) and C (50\% methanol and 33\% chloroform) were CML-selective showing a significant antiproliferating activity against the K562 cell line (CML) with minimal activity against other tested cell lines. However, extractions with mixtures Eth (70\% ethanol) and E (50\% methanol, 33\% ethyl acetate) produced crude organic extracts that are less selective, causing a significant growth inhibition of MH3924A (rat Morris hepatoma) cell line, but minimal anti-proliferative activity against other tested cell lines. It is worth investigating the activities found in Eth and $\mathrm{E}$ extracts missing in extracts $\mathrm{H}$ and $\mathrm{C}$, which cause significant 
inhibition of the MH3924A (rat Morris hepatoma) cell line. Our data argue that the two observed anti-proliferation activities against the K562 (CML) and MH3924A (rat Morris hepatoma) cell lines might be separated.

Based on the extraction method employed and the ability to exert biological effects on an in vitro system, we argued that the active moieties in the organic extraction are not HMW substances, rather LMW substances.

K562 cells are pluripotent cells that are able to differentiate along a megakaryocytic, erythroid, or, to a lesser extent, monocytic lineage. Erythroid differentiation can be induced by a number of compounds including hemin and butyric acid (31). The different organic extracts of D. gibbosa were evaluated for their ability to induce erythroid differentiation in K562 cells. Each extract was able to induce hemoglobin expression above the control levels, however, the Eth extract was the most potent one and induced hemoglobin expression by $>9$-fold-treated cells. Our data show that there is no correlation between antiproliferation activity against CML cells and the ability to induce erythroid differentiation. Eth and $\mathrm{C}$ extracts show comparable anti-proliferation activity against CML, however, they induced hemoglobin expression by 10.8 and 1.7 , respectively.

It is worth noting that the hemoglobin produced in K562 is a fetal hemoglobin, mainly $\gamma$-globin. Increased expression of the endogenous $\gamma$-globin gene is a realistic approach to therapy of $\beta$-globin disorders such as sickle cell anemia and B-thalassemia $(32,33)$. Thus, our mycelium extract has the potential to serve as a therapy for $\beta$-globin disorders.

The observed anti-proliferation activity of the organic extracts of $D$. gibbosa against K562 was attributed to the induction of apoptosis. PARP cleavage assay showed that $\mathrm{E}$ and Eth extracts were active at a concentration above 250-300 $\mu \mathrm{g} / \mathrm{ml}$ to induce apoptosis in treated cells (Fig. 1). Similarly, other organic extracts induce apoptosis in K562 with a comparable potency (data not shown).

Bcr-Abl exhibited uncontrolled tyrosine kinase activity, which accounted for its tumorigenesis. Consequently, inhibitors of the tyrosine kinase activity of Bcr-Abl were developed as an effective molecular therapy for the chronic phase of CML such as Imatinib (STI571; Gleevec). In an attempt to verify the mechanism of action of our $D$. gibbosa organic extracts, we investigated the effect of D. gibbosa extracts on the kinase activity of Bcr-Abl. Treatment with the D. gibbosa extract for $1 \mathrm{~h}$ caused a significant reduction in the amount of phosphorylated Bcr-Abl, implying that the anti-proliferation effect exhibited by $D$. gibbosa might be mediated by substances of the extract that interfere with the phosphorylation process of Bcr-Abl.

Although there are no published reports showing biological activity or substances isolated from $D$. gibbosa, anti-tumor activity from a related species has been reported. $D$. dickinsii (Berk.) Bond et al (34) and D. biennis (Bull.) Fr. (35) showed anti-tumor activity. Active molecules, such as lanostane triterpenoids and lanostane triterpene glucosides, were isolated from fruit bodies of $D$. dickinsii by $70 \%$ ethanol and inhibited the growth of the HL-60 and HCT-15 cell lines. Furthermore, lanostane triterpene glucosides promoted apoptosis in the HL-60 cell line (36).
Upon activation, Bcr-Abl becomes autophosphorylated on multiple tyrosines, making Bcr-Abl tyrosin-phosphorylation a useful indicator of Bcr-Abl kinase activity. The inhibitory effects of $D$. gibbosa fractions on the autophosphorylation of Bcr-Abl showed that fraction F6 was the most potent in decreasing the autophosphorylation activity of Bcr-Abl. In addition, contrary to Imatinib, the D. gibbosa crude extract and fraction F6 dramatically inhibited the phosphorylation of the native Bcr-Abl and the two mutated forms including T315I.

Furthermore, $\mathrm{Ba} / \mathrm{F} 3$ cells harboring Bcr-Abl are able to form colonies in soft agar. These studies showed that Imatinib was able to inhibit colony formation by the $\mathrm{Ba} / \mathrm{F} 3 \mathrm{p} 185$ $\mathrm{Bcr}-\mathrm{Abl}$ cell line. However, it failed to interfere with the growth of $\mathrm{Ba} / \mathrm{F} 3$ p185 Bcr-Abl/T315I and Ba/F3 p185 Bcr$\mathrm{Abl} / \mathrm{E} 255 \mathrm{~K}$ in soft agar. Conversely, treatment of $\mathrm{Ba} / \mathrm{F} 3 \mathrm{p} 185$ Bcr-Abl by either D. gibbosa crude extract or the active fraction F6 caused an inhibition of colony formation by all $\mathrm{Ba} / \mathrm{F} 3$ p185 Bcr-Abl cell lines.

In order to focus on the study of the mechanism of action, it was necessary to determine whether the active fraction F6 directly inhibits the Bcr-Abl kinase activity. Fraction F6 inhibited $56 \%$ of recombinant Abl tyrosine kinase activity in an in vitro kinase assay at a concentration of $100 \mu \mathrm{g} / \mathrm{ml}$. The effect of AG957 on Abl kinase activity is consistent with other reported data since its activity does not depend on the special conformation of the enzyme Abl. Contrary to AG957, the effect of Imatinib in an in vitro Abl kinase assay needed a 5-fold higher concentration than its effect in previous cell culture assays. The effect of Imatinib is more potent in the cell culture assay, since it usually binds to the inactive conformation of the Bcr-Abl protein.

Our study showed the ability of natural product-derived substances to regulate the activity of Abl kinase with yet an undefined mode of action. Several Abl kinase inhibitors are available and were reported to inhibit the native form of Bcr-Abl and also most of its mutations that confer a resistance to Imatinib. However, almost all Abl kinase inhibitors, except VX-680, failed to inhibit the kinase activity of the Abl T315I mutation. Our study illustrated that substances found in the D. gibbosa F6 fraction were able to inhibit the kinase activity and autophosphorylation function of the native $\mathrm{Abl}$ and its mutants, including T315I. The nature and the chemical structure of the active moiety remain to be elucidated.

\section{Acknowledgements}

This study was supported by the Ministry of Science and Technology of Israel, grant no. 3-3500.

\section{References}

1. Mizuno T: The extraction and development of antitumor-active polysaccharides from medicinal mushrooms in Japan (review). Int J Med Mushr 1: 9-29, 1999.

2. Wasser SP: Medicinal mushrooms as a source of antitumor and immunomodulating polysaccharides. Appl Microbiol Biotechnol 60: 258-274, 2002 .

3. Chang ST: A 40-year journey through bioconversion of lignocellulosic wastes to mushrooms and dietary supplements. Int J Med Mushr 3: 299-310, 2001. 
4. Yassin M, Mahajna J and Wasser SP: Submerged cultured mycelium extracts of higher basidiomycetes mushrooms selectively inhibit proliferation and induce differentiation of K562 human chronic myelogenous leukemia cells. Int J Med Mushr 5: 261-276, 2003.

5. Zaidman BZ, Yassin M, Mahajna J and Wasser SP: Medicinal mushroom modulators of molecular targets as cancer therapeutics. Appl Microbiol Biotechnol 67: 453-468, 2005.

6. Petrova RD, Wasser SP, Mahajna J, Denchev CM and Nevo E: Medicinal Mushrooms: A new source for breast cancer therapeutics. Int J Med Mushr 7: 445-446, 2005.

7. Zaidman B, Wasser SP, Nevo E and Mahajna J: Androgen receptor-dependent and independent mechanisms mediates Ganoderma Lucidium activity on LNCaP prostate cancer cells. Int J Oncol 4: 959-967, 2007.

8. Petrova RD, Mahajna J, Reznick AZ, Wasser SP, Denchev CM and Nevo E: Fungal substances as modulators of NF-kB activation pathway. Mol Biol Rep 34: 145-154, 2007.

9. Faderl S, Talpaz M, Estrov Z and Kantarjian HM: Chronic myelogenous leukemia: biology and therapy. Ann Intern Med 131: 207-219, 1999.

10. Li S, Ilaria RL Jr, Million RP, Daley GQ and Van Etten RA: The P190, P210, and P230 forms of the BCR/ABL oncogene induce a similar chronic myeloid leukemia-like syndrome in mice but have different lymphoid leukemogenic activity. J Exp Med 189: 1399-1412, 1999.

11. Sawyers CL, Hochhaus A, Feldman E, et al: Imatinib induces hematologic and cytogenetic responses in patients with chronic myelogenous leukemia in myeloid blast crisis: results of a phase II study. Blood 99: 3530-3539, 2002.

12. Talpaz M, Silver RT, Druker BJ, et al: Imatinib induces durable hematologic and cytogenetic responses in patients with accelerated phase chronic myeloid leukemia: results of a phase 2 study. Blood 99: 1928-1937, 2002.

13. Ottmann OG, Wassmann B and Hoelzer D: Imatinib for relapsed BCR/ABL positive leukemias. Ann Hematol 81: S36-S37, 2002.

14. Gambacorti-Passerini CB, Gunby RH, Piazza R, Galietta A, Rostagno R and Scapozza L: Molecular mechanisms of resistance to imatinib in Philadelphia-chromosome-positive leukaemias. Lancet Oncol 4: 75-85, 2003.

15. Azam M, Latek RR and Daley GQ: Mechanisms of autoinhibition and STI-571/imatinib resistance revealed by mutagenesis of BCR-ABL. Cell 112: 831-843, 2003.

16. Shah NP, Tran C, Lee FY, Chen P, Norris D and Sawyers CL: Overriding imatinib resistance with a novel ABL kinase inhibitor. Science 305: 399-401, 2004.

17. Hochhaus A and La Rosee P: Imatinib therapy in chronic myelogenous leukemia: strategies to avoid and overcome resistance. Leukemia 18: 1321-1331, 2004.

18. Hofmann WK, Komor M, Wassmann B, et al: Presence of the BCR-ABL mutation Glu255Lys prior to STI571 (imatinib) treatment in patients with $\mathrm{Ph}+$ acute lymphoblastic leukemia. Blood 102: 659-661, 2003.

19. O'Hare T, Walters DK, Stoffregen EP, et al: In vitro activity of Bcr-Abl inhibitors AMN107 and BMS-354825 against clinically relevant imatinib-resistant Abl kinase domain mutants. Cancer Res 65: 4500-4505, 2005.

20. Cheetham GM, Charlton PA, Golec JM and Pollard JR: Structural basis for potent inhibition of the Aurora kinases. Cancer Lett 251: 329-9, 2007.
21. Maekawa T, Ashihara E and Kimura S: The Bcr-Abl tyrosine kinase inhibitor imatinib and promising new agents against Philadelphia chromosome-positive leukemias. Int J Clin Oncol 12: 327-340, 2007.

22. Wasser SP, Lewinsohn D and Duckman I: Culture Collection of Higher Basidiomycetes of the Haifa University. Peledfus Press, Haifa, 2002.

23. Acs P, Beheshti M, Szallasi Z, Li L, Yuspa SH and Blumberg PM: Effect of a tyrosine 155 to phenylalanine mutation of protein kinase cdelta on the proliferative and tumorigenic properties of NIH 3 T3 fibroblasts. Carcinogenesis 21: 887-891, 2000.

24. Roehm NW, Rodgers GH, Hatfield SM and Glasebrook AL: An improved understanding of the pathogenesis of CML: A prototype of early neoplasia. Leukemia 11: 1404-1428, 1991.

25. Ray S, Bullock G, Nuñez G, et al: Enforced expression of Bcl-xS induces differentiation and sensitizes CML-blast crisis K562 cells to Ara-C mediated differentiation and apoptosis. Cell Growth Differ 7: 1617-1623, 1996.

26. Lozzio CB and Lozzio BB: Properties and usefulness of the original K-562 human myelogenous leukemia cell line. Blood 45: 321-334, 1975.

27. Leary JF, Farley BA, Giuliano R, Kosciolek BA, La Bella S and Rowley PT: Induction of megakaryocytic characteristics in human leukemic cell line k562: polyploidy, inducers, and secretion of mitogenic activity. J Biol Regul Homeost Agents 1: 73-80, 1987.

28. McGowan AJ, Ruiz-Ruiz MC, Gorman AM, Lopez-Rivas A and Cotter TG: Reactive oxygen intermediate(s) (ROI): Common mediator(s) of poly(ADP-ribose)polymerase (PARP) cleavage and apoptosis. FEBS Lett 392: 299-303, 1996.

29. Weisberg E, Manley PW, Breitenstein W, et al: Characterization of AMN107, a selective inhibitor of native and mutant Bcr-Abl. Cancer Cell 7: 129-141, 2005.

30. Wolff NC, Veach DR, Tong WP, Bornmann WG, Clarkson B and Ilaria RL Jr: PD166326, a novel tyrosine kinase inhibitor, has greater antileukemic activity than imatinib mesylate in a murine model of chronic myeloid leukemia. Blood 105: 3995-4003, 2005.

31. Villeval JL, Pelicci PG, Tabilio A, et al: Erythroid properties of K562 cells. Effect of hemin, butyrate and TPA induction. Exp Cell Res 146: 428-435, 1983.

32. Nagel RL, Fabry ME, Pagnier J, et al: Hematologically and genetically distinct forms of sickle cell anemia in Africa, The Senegal type and the Benin type. N Engl J Med 312: 880-884, 1985 .

33. Labie D, Pagnier J, Lapoumeroulie C, et al: Common haplotype dependency of high $\mathrm{G}$ gamma-globin gene expression and high $\mathrm{Hb} F$ levels in beta-thalassemia and sickle cell anemia patients. Proc Natl Acad Sci USA 82: 2111-2114, 1985.

34. Fujii T, Maeda H, Suzuki F and Ishida N: Isolation and characterization of a new antitumor polysaccharide, KS-2, extracted from culture mycelia of Lentinus edodes. J Antibiot 31: 1079-1090, 1978

35. Ying J, Mao X, Ma Q, Zong Z and Wen H: Icons of Medicinal Fungi from China. Yuehan X (ed). Science Press, Beijing, 1987. Translated.

36. Yoshikawa K, Kouso K, Takahashi J, et al: Cytotoxic constituents of the fruit body of Daedalea dickisii. J Nat Prod 68: 911-914, 2005. 